\title{
FUTURE ASPIRATIONS OF THE ELEMENTARY PUPILS IN SCHOOL OF SAINT ANTHONY, LAGRO, PHILIPPINES
}

\author{
Semorlan, A., Atendido, P., Erbina, E., De Vera, E., Flores M., Mambil, W., \\ Palaganas, G., Pecson, S., Pinuela, P., San Jose, K., Sugay, J., \& Violanta, M. \\ Faculty of School of Saint Anthony, Lagro, Quezon City, Philippines \\ (avaannsemorlan@yahoo.com)
}

\begin{abstract}
The Elementary Christian Living and Good Manners and Right Conduct teachers conducted a survey regarding the dreams of Elementary school students at their respective grade levels. Responses were then gathered in determining the important themes that emerged during the analysis stage. During this process, it was found that the dreams and intentions of the pupils revolve around four themes in the perspectives of "I", "Family", "Others" and "Faith." In the "I" perspective, the following factors are revealed: jobs in the future, materials/gadgets, high academic performance, imaginative/supernatural dreams, positive moods, being rich, having pets, possessing good attitudes, acquiring desired talents/skills, travelling, possessing certain physical attributes, food, health, receiving recognitions, finishing studies, enrolling in prestigious College institutions, receiving blessings, and becoming successful in life. It was found out that the concept of "I" becomes broader as students mature. In the "Family" perspective, some students hope for better family relationships, safety, love, good health, and happiness for their families by supporting their parents and making them proud. The notion of making parents proud and supporting the family is evident in most of the grade 4 to 6 students. The "Others" perspective involves concern for other people like friends, teachers, neighbors and care for the environment, country, and world peace. The last theme discerned was the "Faith" perspective wherein appreciation for God's blessings, becoming closer to God, asking for God's guidance, protection and forgiveness are cited by a few students. The "I" and the "Family" perspectives are given importance by majority of the elementary population. It can be derived from these study's findings that students in the elementary highly prioritize concerns about oneself and the immediate people involved in their lives who are their family members. At this stage, they try to win recognition by showing efforts. These were represented by the results of how the students hoped to have good jobs, attain high grades and please their families because these are the things they view as right or good. It can be assumed
\end{abstract}


that the positive dreams that the children have for themselves and their families are influenced by their belief in the concept of goodness which is a significant teaching of Christ. Further, the findings of this study serve as a challenge to the significant adults in the lives of children such as parents, teachers and guardians to enlighten every child to manifest concern towards other people and to always place God in the center of their dreams and aspirations in life.

Keywords: dreams, Elementary school, intentions, faith, themes

\section{Introduction}

Questions about children's hopes, dreams, wishes or aspirations in life are commonly asked by the elementary teachers to their students. This is usually evident during teacher and student interactions or written activities. Parents ask their children the same questions as well. Although asking a child's dream serves as a common question during formal/informal interactions, not much relevant local studies related to it were found in literatures and in the web sites. Thus, it is pioneering to probe the dreams of children and come up with a research on this facet.

Bukatko and Daehler (2012) explains that when children reach about 7 years of age, there is an element that enters their self-description whereas children describe themselves in terms of typical physical characteristics and activities. Older children, on the other hand, begin to make relational statements that may include one's family members and other people.

Dreams usually denote what a person hopes for or envisions in the future or it could be what every individual fervently prays for. Children in the grade school may dream about themselves or their relation with other people. During spiritual activities, there would be specific moments when people offer their personal intentions through prayers. The essence of long prayers is developed when a person reaches adolescence. Then, it becomes more evident during the adult stage and becomes deeper in the old age. Through this basic observation, the CL/GMRC teachers of the School of Saint Anthony find interest in discovering the dreams that their students would often pray for through an essay activity.

It would be interesting to know the dreams of Elementary students for teachers to be able to capture their attention during interactions and reflective activities. 


\section{Statement of the Problem}

This study examined the dreams of the Elementary students across grade levels. This study addressed the following questions:

1. How do dreams of students vary in each grade level?

2. What are the common dreams shared by the students in each grade level?

3. What are the themes that emerged in the dreams shared by the Elementary students?

4. What are the differences discovered in the dreams of Elementary students as they mature?

\section{Literature Review}

There are theoretical perspectives that explain the development of children in the elementary years. There are also few studies found about the hopes and dreams of children in their school-age years. These theories and studies would be helpful in understanding this study.

\section{Theoretical Perspectives}

Children in the Grade School may also be termed as school age children, or children in elementary years and ages range from 6 to 12 years old. Erikson (cited by Berns, 2010) discussed children at this age are becoming more aware of themselves as individuals. They work hard at "being responsible, being good and doing it right." Erikson viewed the elementary years as critical for the development of self-confidence. Ideally, elementary school provides many opportunities for children to achieve the recognition of teachers, parents and peers by producing things-drawing pictures, solving addition problems, writing sentences, and so on. If children are encouraged to make and do things and are then praised for their accomplishments, they begin to demonstrate industry by being diligent, persevering at tasks until completed, and putting work before pleasure. If children are instead ridiculed or punished for their efforts or they find they are incapable of meeting their teachers' and parents' expectations, they develop feelings of inferiority about their capabilities.

Erikson explains that children in the school-age are in the Industry versus Inferiority stage. In this stage, the child in the school age learns to accept instruction and win recognition by showing effort and by producing "things." The child is developing the capacity to enjoy work. The outcome of this stage for children who receive recognition for their efforts will be motivated to achieve, whereas the children who are ignored or rebuked may give up and exhibit 
helplessness. Some feelings of inferiority are healthy; however, they can prevent children from feeling invincible and taking dangerous risks.

Kohlberg's theory (cited by Berns, 2010), on the other hand, stressed that children in the Elementary years fall in the Conventional stage of the Moral Development theory. This stage emphasizes the mutual interpersonal expectations, relationships and interpersonal conformity of children. What is right among the children in this stage is to live up to what is expected by people close to them or what people generally expect of their role as son, brother, friend, etc. "Being good" is important and it means having good motives and showing concern about others. It also means keeping mutual relationships by showing trust, loyalty, respect and gratitude. The reasons for doing the right things are to know how to be a good person in your own eyes and those of others; caring for others; belief in the golden rule; and desire to maintain rules and authority, which support stereotypical good behavior.

Bukatko and Daehler (2012) stressed that psychologists have long recognized that children live in vastly different circumstances and that these differences can have a dramatic influence on development. He further discussed that Ecological theories in general stress the need to understand development in terms of the everyday environment in which children are reared, a concern that is seldom the focus of many other theories. Bronfenbrenner (cited by Bukatko \& Daehler, 2012) in his ecological systems theory explain five systems that influence the development of the child and these are the following: microsystem (include the home, members of the household, social and educational circumstances, and neighbors); mesosystem (includes the many interrelationships among the various settings within the microsystem); exosystem (social, economic, political, religious and other settings can affect the development either directly or indirectly through their impact on those who care for the child); macrosystem (the broadest context that includes the spiritual, religious values, legal and political practices, and ceremonies and customs shared by a cultural group; and chronosystem (the constantly changing temporal component of the environment that can influence development). In this connection, Lev Vygotsky's socio-cultural theory blends with Bronfenbrenner's theory emphasizing the importance of cultural tools, symbols and ways of thinking that the child acquires from more knowledgeable members of the community.

Moreover, the Dynamic systems theory explains that development is an emerging organization arising from the interaction of many different processes (Lewis, 2000, cited by Bukatko \& Daehler, 2012). One of the more important implications of dynamics systems theory is that development is not controlled or regulated by one particular factor, for example by the brain, the genes, child rearing practices, or any other specific influence. Instead, these various 
components are parts of the cascading process that induces more organized and advanced behaviors or ways of thinking.

Fowler (1982), developed a stage theory of Faith Development which is the most complete organization of concepts of faith within the framework of human development. Schoolchildren belong to stage 2 referred as the "Mythic-Literal" faith. This is when a person begins to internalize the faith attitudes and views of person, primarily adults, other than family members. She/he has an increasing awareness of different faith attitudes in society but still tends to hold on to those of family and religious traditions.

\section{Emotional Development and Family}

Siegler (2006) discussed that children's emotional development is influenced by parents' socialization of their children-that is, their direct and indirect influence on their children's standards, values and ways of thinking and feeling. The author went on discussing that parents socialize their children's emotional development through (1) their expression of emotion with their children and other people, (2) their reactions to their children's expression of emotion, and (3) the discussions they have with their children about emotion and emotional regulation. Each of these avenues of socialization can affect not only children's emotional development but also their social competence.

In addition, Bukatko and Daehler (2012) explained that families are central to the process of socialization, the process by which children acquire the social knowledge, behaviors, and attitudes valued by the larger society. Parents, siblings and others within the family unit are the people with whom the child usually spends the most time and forms the strongest emotional bonds, and they thus exert an undeniable influence on the child's life.

Eisenberg (1986, cited by Siegler, 2006) explained the different levels of pro-social behavior. He cited that recognition of others' needs increases in the elementary school years. In this connection, children increasingly express concern about social approval and acting in a manner that is considered "good" by other people and society.

Moreover, the following levels of pro-social behavior are found predominant among Elementary children:

Level 1: Self-Focused Orientation. The individual is concerned with his/her own interests rather than with moral considerations (predominant mode for younger elementary school children).

Level 2: Needs-Based Orientation. The individual expresses concern for the physical, material and psychological needs of others even when those needs conflict with his/her own (predominant mode for many elementary school children).

Level 3: Approved and/ or stereotyped orientation. The individual justifies engaging or not engaging in prosocial behavior on the basis of others' approval or acceptance 
Semorlan, A., Atendido, P., Erbina, De Vera, E., Flores M., Mambil, W., Palaganas, G., Pecson, S., Pinuela, P., San Jose, K., Sugay, J., Violanta M

and/or on stereotyped images of good and bad persons and behavior (predominant mode for some elementary children).

Level 4: Self-reflective empathic orientation- The individual's judgments include evidence of self-reflective sympathetic responding or role taking, concern with others' humaneness, and/or guilt or positive emotion related to the consequences of one's actions (predominant for few older elementary school children).

\section{Children Dreams/ Hopes for the Future}

In a study conducted in Paris last 2010 about children's hopes, the children under study have positive and hopeful understandings of the future. While the children discuss about global issues such as war and poverty, many have hope in, and believe that we will find solutions to these problems in the future. Such belief in positive futures transpiring is fundamental to a sense of well-being. From a total of 1170 participants, it was found that 70 children explicitly referenced celebrity in some way. Some 76 children- both boys and girls-implicitly identified themselves with the wealthy stars that they admire, and hope to enjoy similar futures. Moreover, the children ambitiously hope to develop varied skills and abilities and to combine multiple and social roles and identities (Enfance et Culture, 2010).

Moreover, in the study of Jarden (2005), the researcher emphasized that the question "What do you want to be when you grow up?, is a question that is asked of children yet little is known about how children and their parents think about their future in terms of employment. In this qualitative longitudinal study of 14 families, the findings highlight the hopes expressed by parents and the nature of parental influence in shaping their children's futures. While children's futures were not developed as précised plans, there were many ways in which they were being "planned." Choices were expanded or narrowed and trajectories mapped out through parents' and children's hopes, dreams and assumptions for what the future would hold. This planning was framed by the family's individualized biographies and their socio-economic status (Sociological Research Online).

Furthermore, Auger, Blackhurst and Wahl (2005) researched on the development of elementary-aged children's career aspirations and expectations. Interviews were conducted with 123 first, third and fifth grade children were observed to examine the types of careers the children wished to have and expected to have. The older children desired careers that were more socially prestigious and less sex-typed compared to those of the younger children. The career thinking of older elementary-aged children was no more specific or realistic than that of younger children, with older children being more likely to aspire for fantasy occupations, (Auger, Blackhurst \& Wahl, 2005) 


\section{Conceptual Framework}

The CL/GMRC teachers had a meeting on coming up with a research to learn about the prayer intentions of the Grade school students. The term prayer intention was unlocked in the lower grade levels as dreams, wishes or hopes. The teachers agreed to collate the data through an essay activity. During the CL/GMRC subject, the teachers had an essay activity and this was their first reflection activity for the school year. The reflection activities written by the students were gathered per grade level and tallied/grouped to determine the themes that emerged during the analysis process.

\section{Conceptual Diagram}

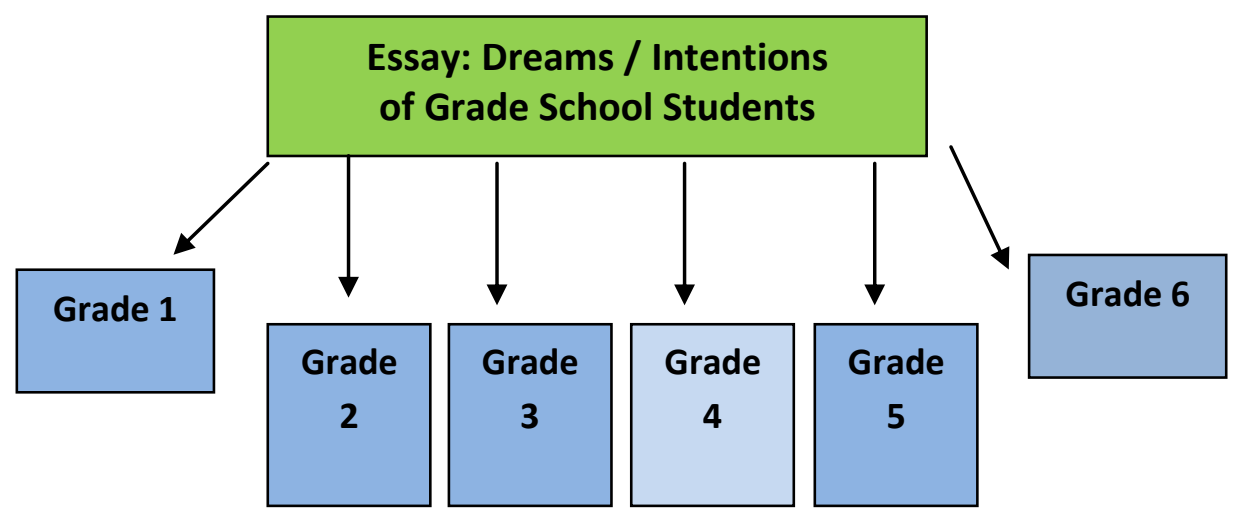

\section{Methodology}

\section{Research Design}

The researchers used the descriptive design in the form of survey in gathering the data. The study is exploratory in nature. The research design is largely an investigative process whereby the researcher gradually makes sense of a social phenomenon by contrasting, comparing, replicating, cataloguing and classifying the object of the study. In this regard, the researchers valued every detail shared by the participants and considered significant for the study. In this connection, based on the meanings discovered from the essay activities of the students, there were themes that emerged that can be relevant to present situations and theories.

\section{Participants of the Study}

The participants of the study were all of the grade school students of the School of Saint Anthony, Lagro, Metro Manila Philippines from levels 1 to 6 . There were 134 students who submitted their reflection activities from grade 1, 132 students in 
grade 2, 150 students in grade 3, 183 students in grade 4, 174 students in grade 5 and 208 students in grade 6 . Table 1 presents the frequency distribution of the participants per grade level.

Table 1: Distribution of Participants per grade level

\begin{tabular}{|c|c|}
\hline Grade Level & Number of Participants \\
\hline Grade 1 & 134 \\
\hline Grade 2 & 132 \\
\hline Grade 3 & 150 \\
\hline Grade 4 & 183 \\
\hline Grade 5 & 174 \\
\hline Grade 6 & 208 \\
\hline Total & $\mathbf{9 8 1}$ students \\
\hline
\end{tabular}

\section{Research Instruments}

The instruments used in this study were the intermediate papers and pens used by the grade school students in writing their intentions and dreams in life. The papers were used for the pupils to enumerate their dreams in the future. An instruction was posted on the black board letting the pupils write their dreams on a piece of paper. Likewise, the researchers had tally sheets to note the responses of the students. A computer and calculator were also used to add the frequency of responses and in formulating the graphs to be used for the research analysis.

\section{Data Gathering Procedure}

The Grade School Christian Living and Good Manners and Right Conduct Department conducted a meeting to brainstorm about the implementation of a research in determining the dreams or intentions of the students. The intention was defined by the teachers especially in the lower grades as dreams, wishes, hopes or aspirations in life. The grades 1 and 2 pupils were guided by their teachers in writing the essay. The pupils who had difficulty in spelling out words were supervised by the teachers. Grades 3 to 6 students wrote their essays independently and the students were given 30- 40 minutes to finish their activity 
and were encouraged to write all their intentions or dreams in life. The pupils wrote their answers in English. Afterwards, the CL/GMRC teachers checked the essays, encoded in the computer excel and the responses were tallied.

\section{Data Analysis}

Frequency/ Percentage as the statistical tool used in this research whereas the responses of the students were grouped and tallied based on the discovered themes, and corresponding percentages in the grade level population were computed. Moreover, tables and charts were likewise used in the tallying of students' responses and data were also compared and analyzed through these means. To further compare and analyze the data gathered, the researchers made use of graphs to view the similarities and differences of responses across grade levels.

\section{Results and Discussion}

This section comprises the presentation, analysis and interpretations of the gathered data based on the instruments used in the study. Graphs are presented to compare the data gathered and to analyze the meanings derived and presented from the formulated graphs.

In the grade one level, it was found that the students were generally particular of dreams about oneself or which is termed in this research as the " $\mathrm{I}$ " perspective. Figure 1 shows that most of the grade 1 students mentioned about the future jobs as well as the toys and gadgets they want to have. These findings indicate that children in grade 1 level mentioned in their dreams the jobs they hope to have someday, and the things they want to have like toys and gadgets.

Sample responses from a grade one pupils were: "I dream of Barbie dolls, fairies, princess meca, hello kitty, flowers, T.V., necklace, books, and shoe," and "I want to be a doctor when I grow up."

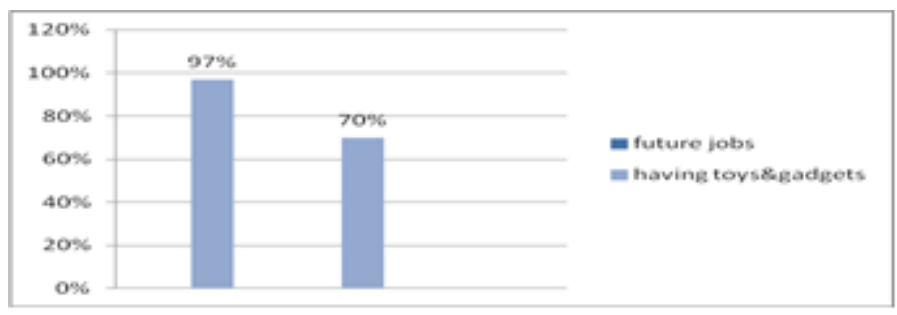

Figure 1: "I" Perspective Graph of the Grade One Population 
As the researchers collated the grade two data, it was found that dreams of the students on this level were categorized into three themes, namely the dreams that revolve on the "I", "Family", and "Others" perspectives.

Figure two presented the graphical representation of the dreams among the grade two students. It was found that most of the grade two population shared dreams about oneself $(71 \%)$. Then, $9 \%$ mentioned dreams in relation to family members like safety and happy relationship among family members. Eight percent, on the other hand, mentioned dreams with other people like gaining more friends and having good relationships with them.

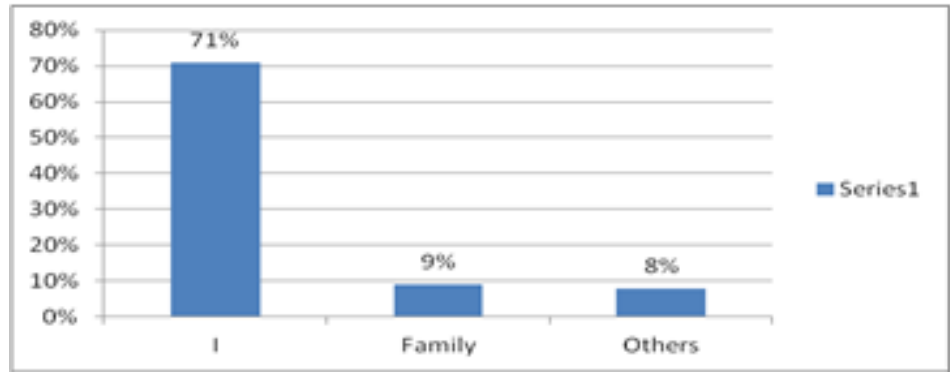

Figure 2: Dreams of Grade 2 Students

In addition, elaborating on the "I" perspective of the grade 2 population, most of the grade 2 students valued the toys and gadgets they want to own in the future $(70 \%)$. This is followed by the jobs they hope in the future $(60 \%)$, super natural dreams like being a super hero (33\%), possessing good behavior $(31 \%)$, becoming rich $(27 \%)$ and getting high grades $(27 \%)$, travelling $(12 \%)$, becoming happy $(9 \%)$, enhancing one's talents $(6 \%)$, obtaining better physical attributes $(4 \%)$ and acquiring specific food (3\%). These data are presented in figure 3 . The previous graphs emphasize that children in grades one and two dreamt of their ideal jobs in the future, as well as, the materials they want to own like toys and gadgets.

The sample responses of the grade two pupils were "I wish to get high grades so my mom and dad will be happy, " and "I want a bike that is purple."

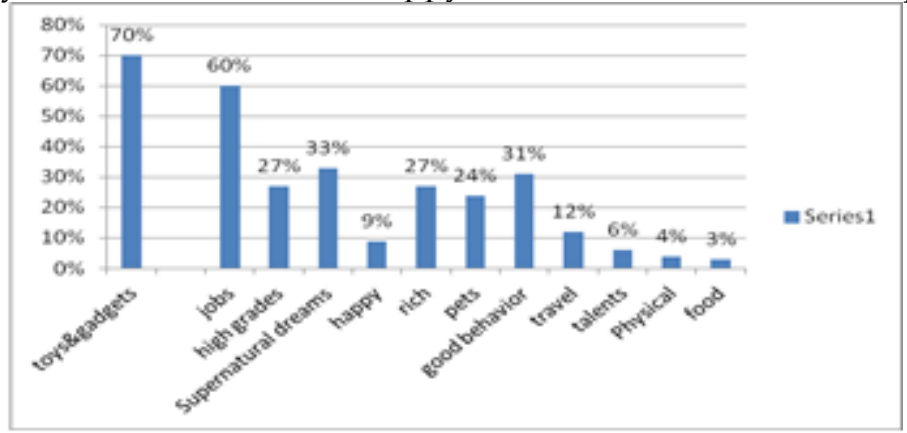

Figure 3:“I” Perspective Graph of the Grade Two Population 
As for the grade 3 students, it was found that majority of the participants in the level prioritized their future jobs in one of their dreams. Sixty five percent $(65 \%)$ of the participants mentioned this. This was followed by the "Family Perspective" which was considered by $29 \%$ of the grade three students and this encompasses the wish for safety, good health and happiness among family members. Thirteen percent $(13 \%)$, on the other hand, shared their dreams in relation to others like good relationships with their classmates and friends. The new theme that emerged in this level is the "Faith" perspective which was cited by around three percent of the said level, indicating a closer relationship with God in the future. Figure 4 presents the graph of the grade 3 responses.

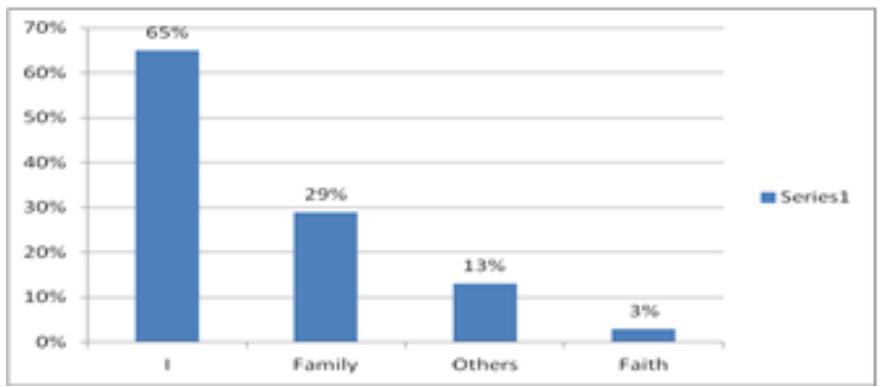

Figure 4: Dreams of Grade 3 Students

When the "I" perspective of the grade three population is further studied, it was discovered that children in this level placed higher weight in obtaining higher grades in class (65\%). This was also followed by the ambitions they aspire in the future $(60 \%)$, then, the materials or gadgets they wish to have $(45 \%)$, and the last one was the pets they hoped to possess someday $(15 \%)$. This depicted that as children reach grade three, they start to become grade conscious than when they were in their younger years.

Sample responses from the grade three pupils were "I wish to get high grades and receive a medal." and " "I want to have a new PSP."

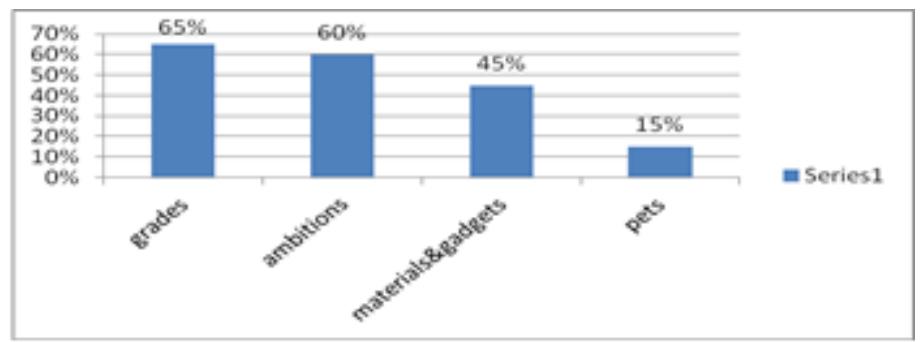

Figure 5:“I" Perspective Graph of the Grade Three Population 
Moreover, the data gathered among the grade four students revealed that grade four students had several dreams for themselves in general (66\%). As for the "I" perspective, there were variety of dreams shared which will be further discussed in the next graph. As for the "Family" perspective, students shared about having happy, safe, healthy, and good relationships among family members. In this connection, to help and please their families and making them proud were also cited by the grade four students. These were written by forty three $(43 \%)$ percent of the grade four population. Sixteen percent $(16 \%)$, on the other hand, mentioned details under the "Others" perspective that talked about classmates, friends, environment, Earth, world peace, and helping the poor. Around 13\% valued Faith in their dreams disclosing protection, forgiveness, guidance and appreciation from God. Figure 6 shows the percentages of the grade four students' responses as grouped according to perspectives.

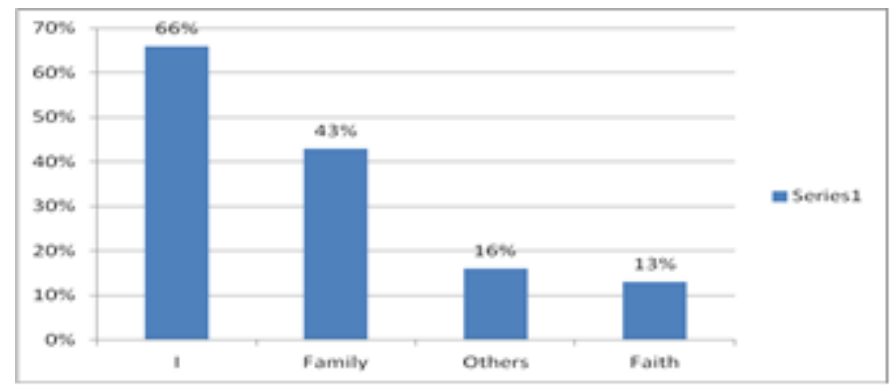

Figure 6: Dreams of Grade 4 Students

When the maximum percentage of the "I" perspective is further explored, it was found that most of the grade four students dreamt of getting high grades $(80 \%)$, and along with these dreams are the aspiration of attaining a specific job (74\%), followed by graduating someday (40\%), obtaining recognitions (35\%), travelling abroad $(32 \%)$, manifesting positive behaviors $(30 \%)$, possessing appealing physical features (20\%), receiving blessings (15\%), and owning particular pets, food and shelter (10\%). Similar with the grade three population, majority of the grade four students placed higher consideration on obtaining high grades in class. Figure 7 presents the graph of the data explored in the " $\mathrm{I}$ " perspective of the grade four students.

Two grade four pupils shared "I will study had to gain high grades, earn more and be a dancer, "and "I will study hard to be the first honor and make my parents happy." 


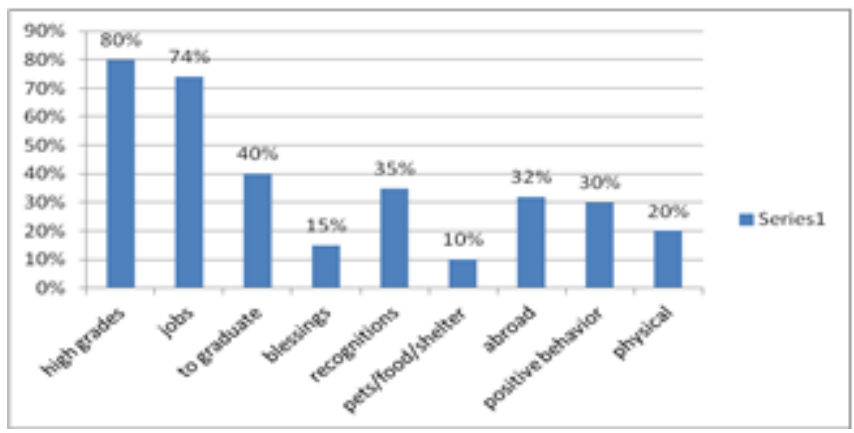

Figure 7: "I" Perspective Graph of the Grade Four Population

Figure 8 displays the graph presentation of the dreams of the grade five students. It can be derived from the graph that similar with the previous levels, the grade five students likewise noted dreams that dealt more on oneself $(88 \%)$ or the "I" perspective. Although about half of the grade five population already developed concern towards their families (41\%) and other people (45\%). In this connection, in the "family" perspective, the students mentioned more on helping their family members especially their parents. As for the "Others" perspective, on the other hand, the students cited peace, friendship and serving others. Further, with regard to the "Faith" perspective, 12\% of the grade 5 population shared their closer relationship with God in the future.

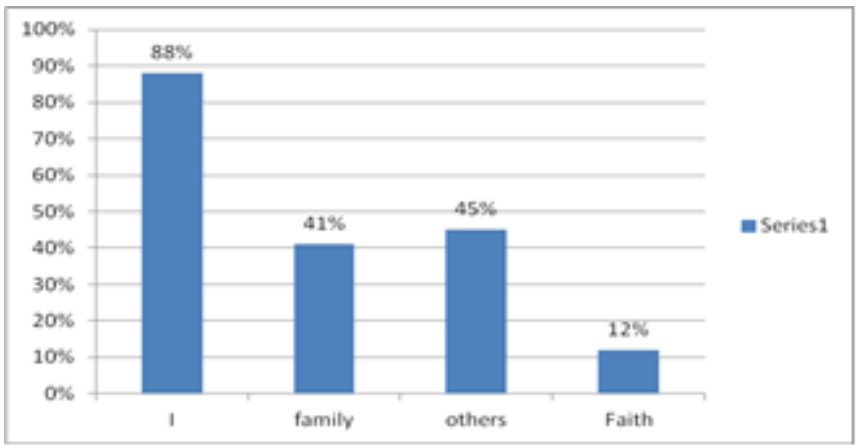

Figure 8: Dreams of Grade 5 Students

Figure 9 reveals the variety of intentions written by the grade five students, yet, the high percentage for dreaming about one's job in the future is very evident $(86 \%)$. This was followed by becoming rich $(8 \%)$, possessing gadgets/materials (4\%) obtaining high grades $(23 \%)$, travelling $(21 \%)$, graduating in the future (18\%) receiving recognitions (16\%), enjoying a good life (11\%), loving and forming a family (9\%), experiencing happiness $(7 \%)$, and small percentages on having talents, pets, good health, good physical attributes, more blessings, pets and imaginative dreams like being a cartoon or computer game character. 
Semorlan, A., Atendido, P., Erbina, De Vera, E., Flores M., Mambil, W., Palaganas, G., Pecson, S., Pinuela, P., San Jose, K., Sugay, J., Violanta $M$

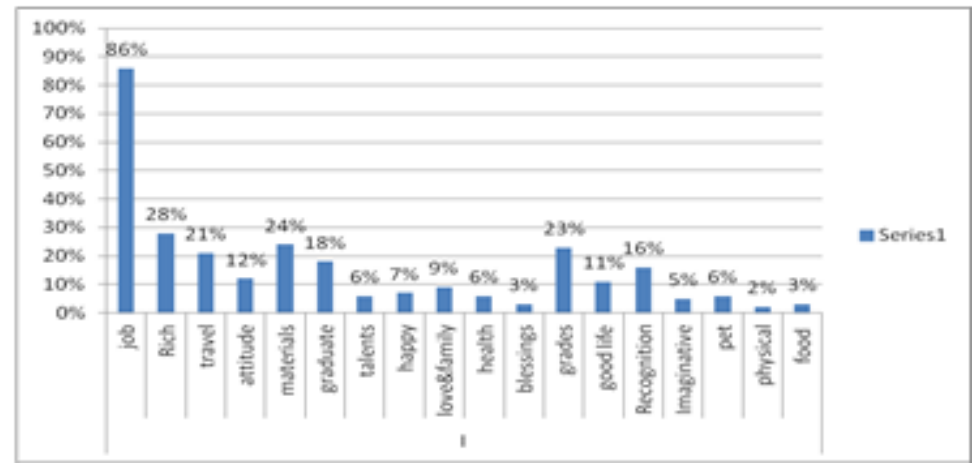

Figure 9:“I” Perspective Graph of the Grade Five Population

A grade five student disclosed "I dream to become rich, to be a doctor, make a school for the poor children, and donate a big amount of money for the poor children."

Figure 10 shows that the intentions of the grade 6 students dealt more on oneself as evidence by the $90 \%$ percentage tallied in their responses. This is in connection with the other Elementary Levels stressing the "I" perspective as highly prioritized when the dreams of the grade school students were asked. In addition, $26 \%$ of the grade six population emphasized the special roles of their families in the dreams they shared like to help and support one's family in the future and making their parents proud someday. As for the "Others" perspective which generated $24 \%$ of the grade six population, the students cited their friends and serving and helping people in need. Lastly, only around $6 \%$ among the grade 6 students mentioned about being closer to God in the future.

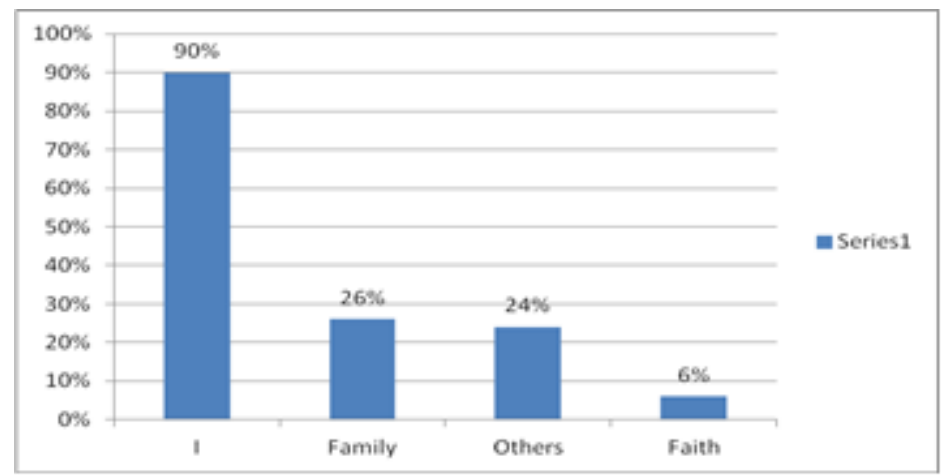

Figure 10: Dreams of Grade 6 Students

As the "I" Perspective of the grade six students was further explored, it was very evident that majority of the grade six students were extremely focused on their job and career in the future considering that students in this level are graduating students. There was a big difference observed when compared to other 
factors. Obtaining the job dreamt was shared by $85 \%$ of the grade six population, and this was followed by travelling (28\%), becoming rich $(25 \%)$, receiving recognition $(2 \%)$, graduating in college and getting desired course $(20 \%)$, purchasing wanted gadgets or materials (14\%), having a family $(9 \%)$, enrolling on a prestigious school in college $(9 \%)$ and small percentages on possessing good behavior, being healthy and getting into sports, receiving high grades, talents and skills, becoming happy and attaining imaginative dreams.

A grade 6 pupil wrote "I want to become a doctor in the future because if my parents are sick, I will cure them and I want to help people."

It can also be discerned that as children reach grades five and six, few students would already mention about having a family in the future. Serving/helping the family and other people in need was also apparent in grades 4 and five.

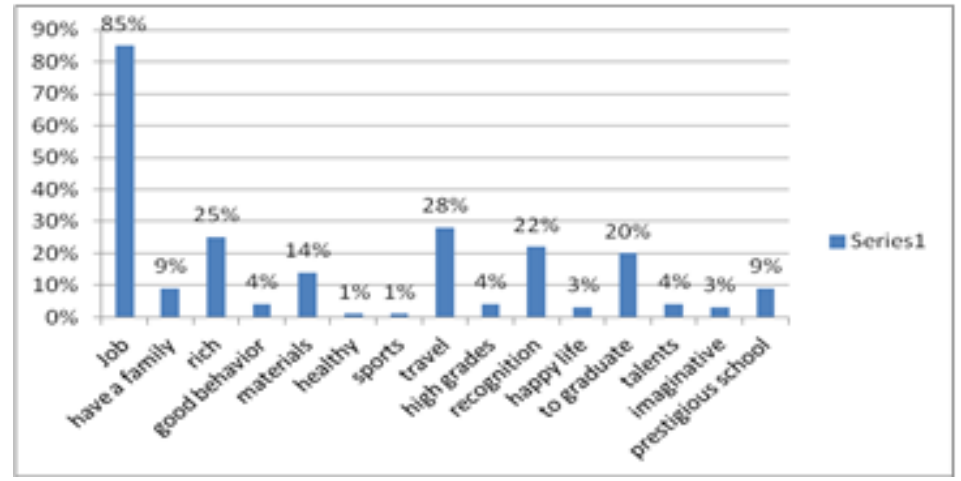

Figure 11:“I” Perspective Graph of the Grade Six Population

It can be derived from these findings that students in the elementary highly prioritize concerns about oneself and the immediate people involved in their lives who are their family members. Erikson (cited by Bukatko \& Daehler, 2012) explains that children in the Elementary School years are becoming more aware of themselves as individuals and they are working hard at being responsible. At this stage, they try to win recognition by showing efforts. These were represented by the results on how the students hoped to have good jobs, attain high grades, and please their families because these are the things they view as right or good. This is in support of Fowler's Faith Development (cited by Stokes, 1982) emphasizing school-aged children adapt the "Mythic -Literal" faith which is a strong belief in justice, a concept of moral righteousness based on ethics. Although, few students mentioned the hopes to have deeper faith in God, it can be assumed that the positive dreams that the children have for themselves and their families are influenced by their belief in the concept of goodness which is a significant teaching of Christ. 
Further, the findings of this study serves as a challenge to the significant adults in the lives of the children like the parents, teachers, and guardians to enlighten every child to manifest concern towards other people and to always place God in the center of their dreams and aspirations in life.

Table 2 presents the summary of findings of the percentages generated from the grade school students' responses when grouped according to the four themes discovered.

Table 2: Summary of Percentages

\begin{tabular}{|c|c|c|c|c|}
\hline Grade Level & $\begin{array}{c}\text { "I" } \\
\text { Perspective }\end{array}$ & $\begin{array}{c}\text { "Family" } \\
\text { Perspective }\end{array}$ & $\begin{array}{c}\text { "Others" } \\
\text { Perspective }\end{array}$ & $\begin{array}{c}\text { "Faith" } \\
\text { Perspective }\end{array}$ \\
\hline Grade 1 & $97 \%$ & 0 & 0 & 0 \\
\hline Grade 2 & $71 \%$ & $9 \%$ & $8 \%$ & 0 \\
\hline Grade 3 & $65 \%$ & $29 \%$ & $13 \%$ & 3 \\
\hline Grade 4 & $66 \%$ & $43 \%$ & $16 \%$ & $13 \%$ \\
\hline Grade 5 & $88 \%$ & $41 \%$ & $45 \%$ & $12 \%$ \\
\hline Grade 6 & $90 \%$ & $26 \%$ & $24 \%$ & $6 \%$ \\
\hline
\end{tabular}

It can be realized from the table that majority of the grade school population placed higher priorities on dreams that concern oneself. This is also in relation to the study conducted by Erbina, Flores, Pinuela, Palaganas, San Jose, Semorlan and Violanta (2013) wherein the results in their new study showed that Elementary pupils tend to be more concerned with individualized activities, considering that few percentage spend time with other people. Grade one students stressed valuing their personal dreams, and this is followed by the grades 6 and 5 levels respectively. It was also discovered that there are increasing percentages in the Family, Others and faith perspectives from grades three to six levels indicating that students place higher concerns over their families and other people as they mature, and a few intend to be more faithful to God as they mature. Yet, a slight drop of percentage could be noticed as children reach their sixth grade which could indicate how students became more serious and focused in attaining their personal dreams as graduating students.

Theoretically, Erikson (cited by Berns, 2010) discussed children during their school age work hard at "being responsible, being good and doing things right. Likewise, elementary school children hope to achieve the recognition of teachers, parents and peers. This theory supported some of the responses of the 
grade school students revealing their aspirations to obtain high grades, receive recognitions and to make their parents proud. This is also in line with Kohlberg's theory (cited by Berns, 2010), emphasizing that what is right among the children in this stage is to live up to what is expected by people close to them, "being good," and doing the right things. Siegler (2006) also explained that Elementary children increasingly express concern about social approval and acting in a manner that is considered "good" by other people and society. It could be observed that most of the responses written by the grade school children were all positive in nature, and being "good" to oneself and others could be established in their varied sharing. The children's positivity in their insight is also related to a study conducted in Paris (2010) about hopes of children wherein the Elementary students under study have positive and hopeful understandings of the future.

Although, several theorists explained several factors that may influence a child's psychological or behavioral perspectives and shaping values of children come in different perspectives (Bukatko \& Daehler, 2012). And one of the most influential factors in every child's development, emotionally speaking, is one's family. It was emphasized by Bukatko and Daehler that parents, siblings and others in the family unit are the people with whom the child usually spends the most time and forms the strongest emotional bonds. With regard to development, Parungao (2011) explained that the development of an individual or a community is exhibited in external behavior that provides the empirical evidence for measuring significant change. The development of the changes of pupils' aspirations is apparent in every grade level and these aspirations are influenced by different factors. In this connection, Atendido, De Vera, Mambil and Semorlan (2014) explained in their recent study that family serves as the top consistent factor that makes the Elementary pupils happy. They enjoyed the different activities and experiences they had with their family members. In relation to this, Erbina, Mambil, Pecson, Pinuela, Semorlan and Sugay (2014) concluded in their research how family serves as a motivating factor among Grade School pupils in dealing with their school activities.

\section{The Revised Framework}

Based on the findings and analyses generated, a new framework could be formulated which depict the connections of the themes discovered in relation to the dreams of the grade school students as they mature. 


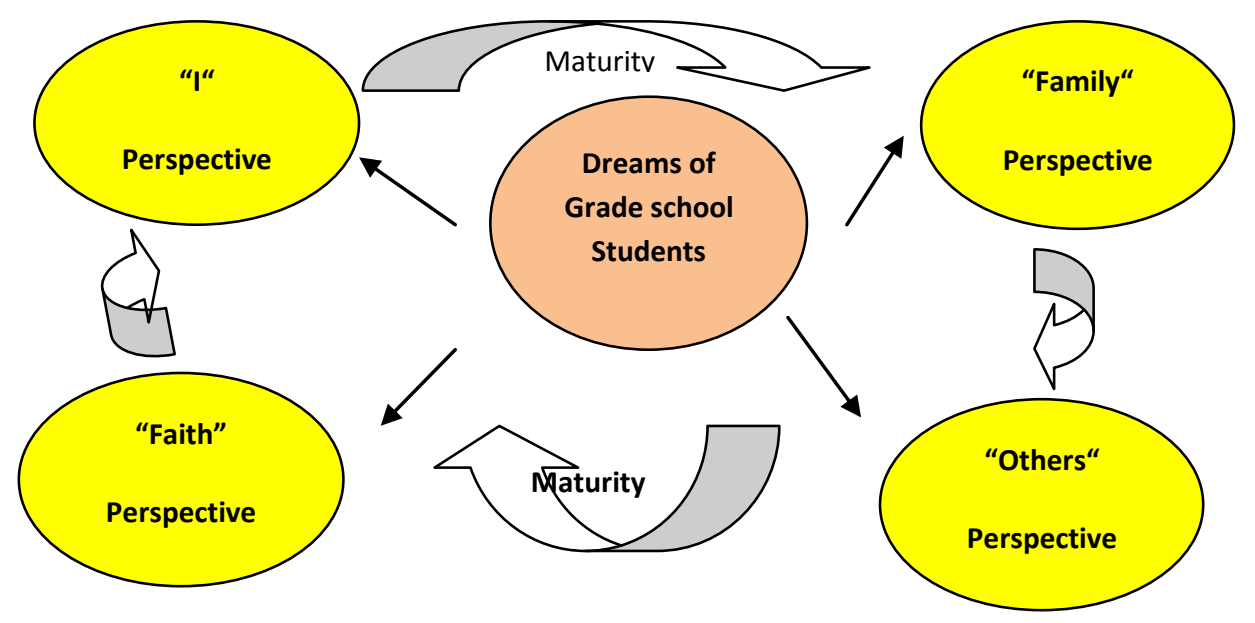

\section{Conclusion and Recommendation}

Determining the intentions or dreams of children is inspiring for teachers and parents. This encouraged the Elementary CL/GMRC teachers to conduct a study in discovering the dreams of students from grades 1 to 6 . This research is descriptive in nature, and the needed data are gathered through an essay writing activity. All the grade school students were requested to write an essay about their intentions in life and this was recorded as one of their reflection activities. During the data gathering and analysis procedures, the responses of the students were noted and studied and it was further ascertained that the answers shared by the pupils fall into four perspectives namely, the "I", "Family", "Others" and "Faith" Perspectives.

There were varied factors revealed in every perspective or theme. The " $\mathrm{I}$ " perspective gained the highest percentage in all levels and the top responses found for this theme included the desired job in the future, materials/gadgets dreamt to possess someday and high grades wished to obtain. In addition, the "Family" perspective was the secondary theme found in the study. This was the next factor prioritized by most of the grade school students next to their personal intentions. Concern for others came as the third priority among the grade school students. The percentages of these perspectives increase as students mature.

Very few of the grade school population mentioned God in their essays. It can be assumed that deepening one's faith in God in the future is not that significant among the Grade school students. Yet, the concept of "goodness" valued by the students may also prove relevant to the children's value of faith because doing good is Christ like or God- oriented.

Based on the data gathered, and in relation to this study's statement of the problem, the following conclusions are revealed: first; the dreams that transpired in each grade level vary. In the grade one level, the students in general shared their dream jobs and materials in the future. While in the grade two level, most of 
the students shared dreams about to oneself, and few mentioned dreams in relation to their families and other people. For the grade three level, on the other hand, more than half of the students dreamt of obtaining high grades followed by their dream jobs and materials. Very few students cited the significance of faith in the future. Likewise, in grades four, five and six, high percentages of the student population cited dreams about oneself, followed by dreams in relation to their family members. Then, some displayed concern for other people's welfare, and few of the students shared intentions of being closer to God. Second; the common dreams shared by the students in each grade level dealt on dreams about oneself. Majority of the students in the lower grades envision their dream jobs and the wish to possess certain materials and gadgets. Students in grades three and four prioritized obtaining high grades to make their parents proud. Grades five and six students valued the jobs they hope someday, and considering helping and serving their parents in the future. Third; there were four themes that emerged in the study. The first theme is the "I" perspective, which is defined as dreams that dealt more one's personal hopes. The next theme was the "Family Perspective" which is described as the students' dreams relating to their family members. The "Others" perspective, on the other hand, served as the third theme, and this dealt on students' concern to other people like their friends, classmates and neighbors. The last theme realized was the "Faith" perspective which is characterized by the closer relationship of the children to God in the future. Fourth; the changes or dream transitions found in the dreams of the students across levels are the variety of dreams discovered as each child matures. In the grade one level, dreams were only encapsulated in the "I" perspective. Few percentages among the grade two students, on the other hand, already cited dreams about one's family, friends, classmates and relationship with God. The dreams of the students especially in the "I" perspective became broader in the next level as several dreams were already shared. Dreams in relation to "Family" and "Others" perspectives increase in percentages as the students mature. Yet, the "Faith" perspective remains to comprise a few percentage in the whole grade school population.

\section{Recommendations}

First; the findings of this study carry implications for the enlightenment of the significant adults in the lives of the children like the teachers, parents, guardians, administrators, counselors and others. In this regard, these significant adults in the lives of the children should deepen their relationship with God so as to imbibe in the children the significance of putting God at the center of every person's life. Second; since this study contributes to the awareness of the general body of knowledge, a summary of this study could be submitted to some publications to update the people of their special roles on shaping the values of the children. 
Taking into consideration that as each generation passes, developing the values of the children remains to be challenging. Thus, it is still a powerful notion to emphasize that the children/youth are the hopes of the future. Third; future researchers could also explore on other factors or enrich this study. A comparative study could be investigated like comparing the dream transition of the each student every grading period/quarter to observe the changes noted. In this connection, a longitudinal study could also be applied to determine the changes of dreams that developed in every participant under study. Likewise, follow up interviews could also be conducted to the participants in the study to further understand the reasons behind every person's dream, and what influence their aspirations in life. Lastly, the dreams in the higher grade levels could be explored as well to enrich the comparisons of data.

\section{References}

Atendido P., De Vera, E., Mambil W.J., \& Semorlan, A. A. (2014). Factors that make elementary pupils happy. Philippines: School of Saint Anthony.

Auger, R.W., Blackhurst, A. E., Wahl, K. H. (2005). The development of elementary-aged children's career aspirations and expectations. Professional School Counseling, Apr2005, 8(4), p322.

Berns, R. (2010). Child, family and school community $8^{\text {th }}$ Edition. USA: Wadsworth Cengage Learning

Bukatko, D., \& Daehler, M. W (2012). Child development: A thematic approach. USA: Wadsworth Cengage Learning.

Enfance et Cultures. (2010). The children's high hopes. Retrieved July 17, 2012 from, http://www. Enfanceetcultures.culture.gouv.fr

Erbina, E.Y., Flores, M., Palaganas G., Pinuela, G.P., San Jose, K.E, Semorlan, A.A. \& Violanta, M. (2013). Activities that elementary pupils value at home. Philippines: School of Saint Anthony.

Erbina, E.Y., Mambil, W.J., Pecson, A.S., Pinuela, G.P., Semorlan, A.A., \& Sugay, J.O. (2014). Factors that motivate grade school pupils to go to church and school. Philippines: School of Saint Anthony

Harden, J. (2010). Hopes for the future: Parents' and children's narratives of children's future employment orientations. Retrieved July 17, 2012 from, http://www.socresonline.org.uk/17/2/13.html

Parungao, J. (2011). Values and the communication of change: The value filters of the nlp communication model applied to Aetas in Loob Bunga Zambales. University of Malaya: JATI: Journal of Southeast Asian Studies, 16, pp 177-193.

Siegler, R. (2006). How children develop. USA: Worth Publishers.

Stokes, K. (1982). Faith development. New York: William H. Sadlier, Inc. 